\title{
ENDEL KÕKSI \\ ABSTRAKTSETEST MAALIDEST
}

Kogu abstraktne kunst polegi muud kui inimese sisemaailma nähtavaks tegemine. Ja kuigi üksikud väljendused on kahtlemata subjektiivsed, on kõik kokku objektiione pilt inimvaimust, nii nagu me seda praegu kujutada oskame. ${ }^{1}$

Endel Kõks, 1970. aastad

Kunstnik Endel Kõks (1912-1983) kuulub ühte põlvkonda eesti kunsti klassikute Elmar Kitse ja Lepo Mikkoga. Pärast Kitse ja Kõksi debüüti 1939. aastal Tallinnas Kujutava Kunsti Sihtkapitali Valitsuse (KKSKV) näitusel hakati neist kolmest rääkima kui lootustandvast Tartu kolmikust. Paraku läks elu aga teisiti. 1944. aasta sügisel sattus Endel Kõks haavatud sõdurina Saksamaale, Kits ja Mikko jäid Eestisse. Oma ülejäänud elu elas Kõks paguluses, rändas läbi terve maailma, kuid ei saanud kordagi tagasi koju. Peamiselt sai pagulasaegset loomingut hinnata mustvalge ajakirjanduse vahendusel. Kunstniku eluajal jõudis Eestisse küll tema töid, enamasti graafikat, kuid see ei andnud tema loomingust ja selle tasemest süstemaatilist ülevaadet. Abstraktsetest maalidest sai aimu mõne pildi järgi, mis jõudsid Eesti Kunstimuuseumisse alles pärast kunstniku surma. Nii kujunes temast nõukogudeaegses kunstiteaduses peaaegu millelegi toetumata mulje kui keskpärasest maalijast ja eriti kui nõrgast abstraktsionistist, kuid mille lükkaksin otsustavalt ümber, toetudes aastatel 2008-2011 pagulaskunstinäitust ${ }^{2}$ ning 2011-2013

\section{DOI: http://dx.doi.org/10.12697/BJAH.2016.11.07}

1 Endel Kõks kirjas Silvia Hinnomile 1970. aastatel. Koopia autori valduses.

2 Näitus „Eesti kunst paguluses“, Kumu (03.09.2010-02.01.2011), Tartu Kunstimuuseum (23.02.201130.04.2011). Kuraatorid: Kersti Koll, Reet Mark ja Tiiu Talvistu. 
Endel Kõksi isikunäitust ${ }^{3}$ ette valmistades ${ }^{4}$ tehtud järeldustele, mida olen täiendanud väliseesti kunstiajaloolaste ja kunstnike arvamustega

Esimese ülevaate Kõksi loomingust kirjutas kunstiloolane Eevi End kohe pärast kunstniku surma ning seejärel avaldas veel ühe artikli 1992 aastal. ${ }^{5}$ Tagasivaateid meistri loomingule tegid kunstnikud Olev Mikiver ning Abel Lee. ${ }^{6}$ Põhjaliku ülevaate Kõksi abstraktsest loomingust, paraku küll ainult 1960. aastate keskpaigani, on kirjutanud kunstiajaloolane Paul Reets. ${ }^{7}$ Nimetatud artiklile pole aga lisatud ühtegi pilti ning seetõttu on kohati võimatu aru saada, millistest töödest käib jutt.

1945. aastaks oli Kõks demobiliseeritud ning elas DP-laagris Geislingenis, ühes suuremas pagulaseestlaste kogunemiskohas Saksamaal. Elu oli karm, kuid kunstnikule oli hea see, et võitjad korraldasid saksa rahvale hulganisti rändnäitusi. Kompensatsiooniks Hitleri valitsusaastatele eksponeeriti seal moodsa kunsti klassikat Euroopa muuseumide suurepärastest kogudest, samuti saksa ekspressionistide loomingut. Nii võis Kõks 1951. aastal väita, et on näinud sadu abstraktseid maale. ${ }^{8}$ Sellel ajal elas ta juba Rootsis Örebros, kus sai endale hea ateljee. Järgnevatel aastatel meenutab Kõks väga 1957. aastal Moskvasse saabunud Ülo Soosterit, kes hakkas järjekindlalt läbi joonistama modernismi klassikute töid kubismist metafüüsilise maali ja sürrealismini. Kõks näib tegevat sama.

Paul Reets on esile tõstnud aastaid 1952-1956, oletades, et need olid vastuoludest rasked töötamise aastad. Üks takistusi oli tema arvates Kõksi pallaslik maalikool, mis oli alalhoidlik ja kinni kubismi hilistes suundumustes. ${ }^{9}$ Oma otsinguid näitas kunstnik 1954. aastal Örebro kunstihallis toimunud isikunäitusel, mis kujunes kokkuvõtteks aastatel 1947-1954 tehtud töödest. ${ }^{10}$ Suure osa võtsid enda alla picassoliku deformatsiooniga figuraalsed maalid, nagu näiteks „Kunstnik ja modell“ (1954) ja pigem

3 Näitus „Endel Kõks. Vapruse, vabaduse ja rõõmuga“, Tartu Kunstimuuseum (14.11.2012-24.03.2013). Kuraatorid: Reet Mark, Reet Pulk-Piatkowska ja Tiiu Talvistu.

Seoses uurimistööga Endel Kõksi loomingust on siinkirjutaja viibinud korduvalt USA-s, Kanadas ja Rootsis.

Eevi End, „Endel Kõksi surm. Üks epohh väliseesti kunstielus on lõppenud“, Eesti Päevaleht (Stockholm), 14.12.1983, 6; Eevi End, „Avangardne Kõks“, Tulimuld, 2 (1992), 71-80.

6 Olev Mikiver, „Endel Kõksi mälestades“, Teataja (Stockholm), 21.12.1983, 8; Abel Lee, „Endel Kõksi mälestades", Vaba Eestlane (Toronto), 12.01.1984, 7

Paul Reets, „Ajajark nimega abstraktne, Tulimuld, 2 (1987), 80-86.

9 Reets, „Ajajärk nimega abstraktne“, 80-81.

10 Endel Kõksi isikunäitus, Konsthallen Örebro (27.11.-8.12.1954). Näitusel oli eksponeeritud 65 õlimaali, 20 temperat ja guašši, 41 joonistust ja graafikat. analüütilisest kubismist välja kasvanud, otsekui mosaiigitükkidest koosnevad mustakontuurilised, aga ka kontuurideta, geometriseeritud figuuridega kompositsioonid, näiteks „Ratsutavad klounid“ (1954) ${ }^{11}$ Mõlema variandi puhul on foon abstraktne. Esines aga ka klassikalist joonistust abstraktsel tagapõhjal ja peaaegu täiesti abstraktset figuurimaali ning täiesti realistlikke natüürmorte ja linnavaateid. Karin Luts oli Kõksi suhtes üsna kriitiline, väites, et „,see kõik on väga banaalne ja pateetiline segu naturalismist ja järelimpressionismist ja mingist böcklinismist!12 /---/ Sellest näitusest jääb mulje, et K. on omad head maalija oskused ühendanud sisuga, mida tal pole aega olnud kujundada selleks, mida nimetatakse kunstiks. ${ }^{\text {“13 }}$ Seega varjutasid Kõksi vormiotsinguid tema tööde literatuurne ja jutustav laad. See jäi teda painama elu lõpuni ja just need tööd jõudsid kõige rohkem ka Eestisse.

Peab rõhutama, et eespool mainitud teemad - realistlikud linnavaated, deformeeritud ja geometriseeritud figuuridega kompositsioonid, portreed, tsirkusestseenid - ei kao tema loomingust ka kõige ägedamal abstraktsiooni perioodil. See annab Max Lasbergile põhjust 1962. aasta märkida, et Kõksil ei ole oma äratuntavat käekirja. ${ }^{14}$ 1963. aastal märgib Kõks, et teda pole „kindel nägu“ kunagi veedelnud. ${ }^{15}$ Alur Reinansi sõnul pidas Kõks seda enda tugevuseks elu lõpuni. ${ }^{16}$ Veel märkis Kõks, et luua ei saa ebateadlikult või mängides nagu laps, „vaid see nõuab inimese

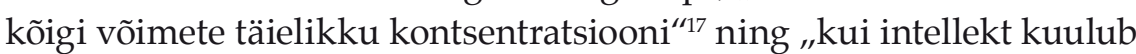
inimese juurde, miks mitte katsuda temale rajada kunstiloomingut; ega tunne selleks ainuüksi võimalusi ei anna.“18

Esimese täiesti abstraktse töö maalis Kõks nii Eevi Endi („Rahutus“) kui ka Paul Reetsi („,Konflikt“) arvates aastal 1956. ${ }^{19}$ „,Rahutusest“, mis meenutab veidi Jackson Pollocki loomingut, on olemas mustvalge foto ja see pole sama töö, millest räägib Reets. Mõlemad märgivad, et tegu on veenva ning läbitunnetatud abstraktsusega, mitte enam vormiotsin-

11 Mustvalgel fotol.

12 Arnold Böcklin (1827-1901) on üks tuntumaid sümbolistliku maalikunsti esindajaid. Maalis müstilistel ja süngetel maastikel mütoloogilisi, rõhutatud tunnetega kajastatud sündmusi. Maalil domineeris süžee vormi ees.

13 Eesti Kultuurilooline Arhiiv [EKLA], f 349, m 52:5.

14 Max Lasberg, ,Ystadi muljed“, Mana, 4 (1962), 302

15 Endel Kõks ,Vabadus on loomingu põhiline vajadus", Eesti Päevaleht (Stockholm), 27.04.1963, 1 16 Alur Reinans, „Endel Kõksist ja eesti kunstist paguluses“, Akadeemia, 1 (2007), 112.

17 Kõks, ,Kaasaegse kunsti probleeme“, 269.

18 Arno Vihalemm, „Kaks õde: kiri kolleegile“, Tulimuld, 6 (1952), 361; vt ka Tulimuld, 1 (1953), 40-47. (ilmst mõnes joonestusbüroos Örebros), mis on dateeritud aastaga 1952. 


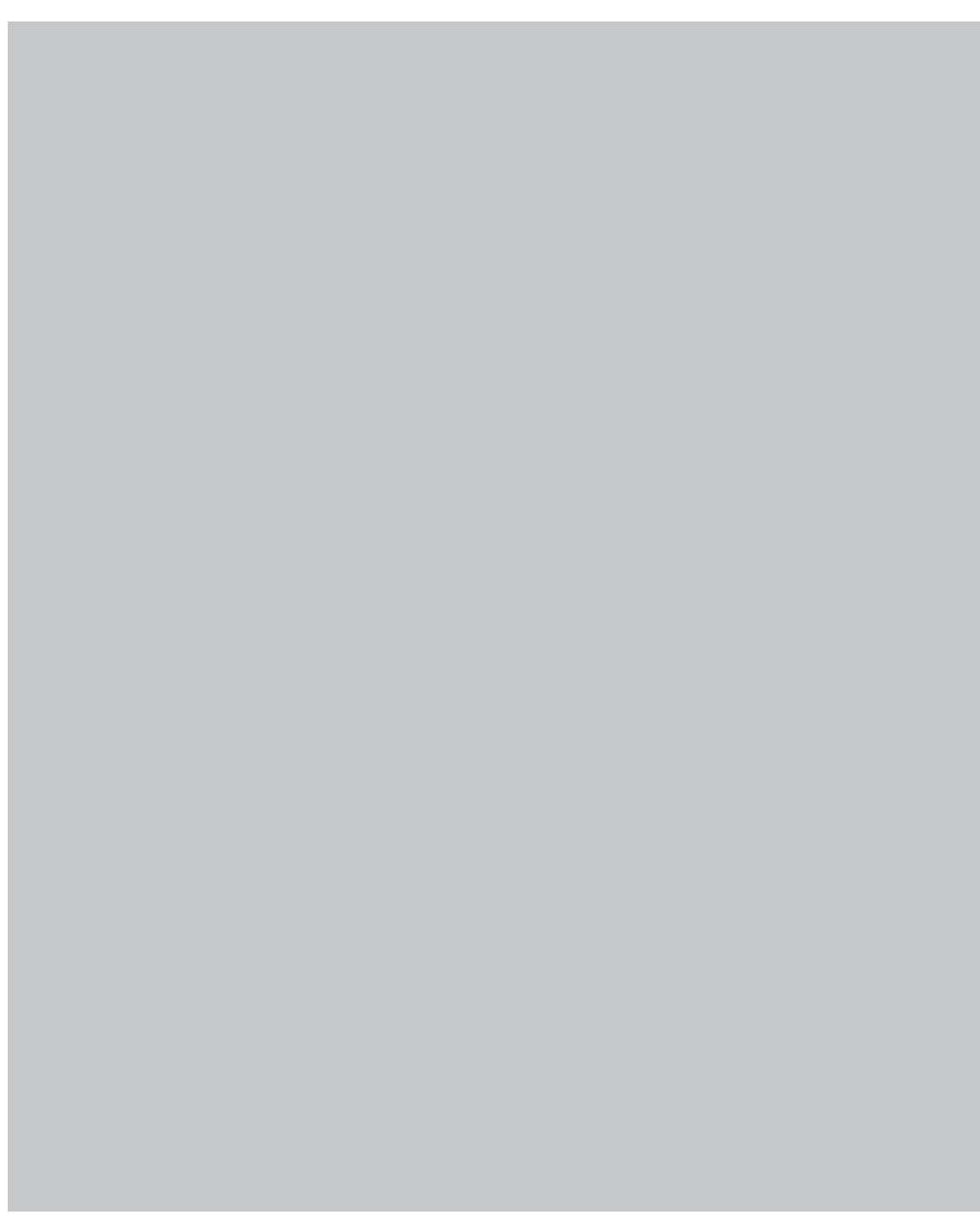

Ill. 1. Endel Kõks, Rõõmus silmapilk, õli lõuendil, 1959. Underi ja Tuglase Kirjanduskeskus.

guga, ning Reets konstateerib, et Kõks on end Pallasest lahti raiunud. ${ }^{20}$ Aastatel 1956-1960 loodud abstraktsioonid - „Kompositsioon“ (1958) „Rõõmus silmapilk“ (1959), „Kujundid rohelisel foonil“ (1960) - on üles ehitatud rõõmsavärvilise koloriidi ja joonte mõjule ning näitavad sugu-

20 End, „Avangardne Kõks“, 73; Reets, „Ajajärk nimega abstraktne“, 81.

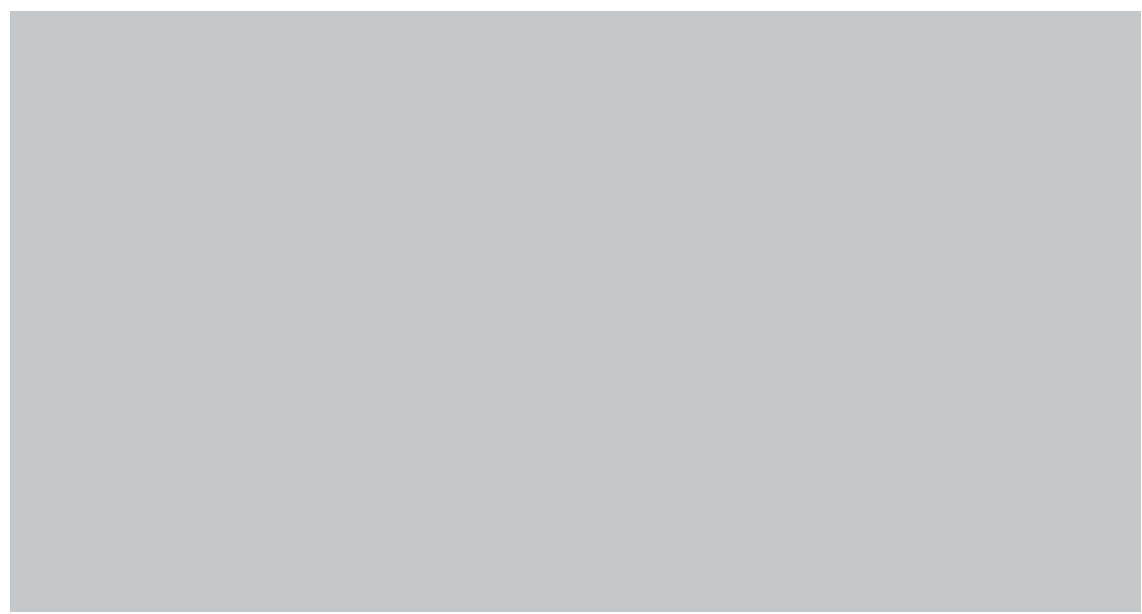

Ill. 2. Endel Kõks, Muinasjutt, õli lõuendil,

1958. Asukoht teadmata.

lust Vassili Kandinsky abstraktsete töödega. Meenutades Kõksi õpetaja Ado Vabbe Kandinsky-meelsust, pole see üllatav. Kuivõrd on siin tegemist pallasliku kooli hülgamisega, on iseküsimus. Sarnasust on neis ka Arshile Gorkyga, kelle töid ta võis näha 1953. aastal toimunud Ameerika moodsa kunsti näitusel Stockholmis. ${ }^{21}$

Vähemalt seitsmest abstraktsest pildist koosneva komplektiga esines Kõks 1958. aastal eesti kunstnike ühisnäitusel Helsingis ja Nürnbergis. ${ }^{22}$ Mõlema näituse arvustustes peeti tema töid parimateks. ${ }^{23}$ Vaadates neid näiliselt vaba ning spontaanse tundega loodud maale, tundub uskumatu kunstniku rõhutatult intellektuaalne lähenemine.

Järgmiste oluliste tööde puhul pean toetuma varasematele kirjutajatele. Paul Reets nimetab abstraktsiooni arengus oluliste teetähistena maale, mida olen näinud ainult mustvalgete fotodena. Need on "Muinasjutt" (1958), „Eile ja täna“ (1959) ja „Kompositsioon“ (1960). Eevi Endi nimetatud "Signal från Merrymann'i" foto on olemas Kõksi arhiivis samuti mustvalgena. Kahes esimeses pildis kasvavat oluliselt värvi osatähtsus.

21 Näitusel „Ameerika 12 kaasaegset maalijat ja skulptorit” Liljevalchsi kunstihallis esinesid Ivan Albright, Stuart Davis, John Kane, Morris Graves, Edward Hopper, John Marin, Ben Shahan, Jackso Pollock, Arshile Gorky, Alexane, Moszak.

22 Näitus „Eesti moodne kunst", Hörhammeri galerii, Helsingi (25.01.-09.02.1958); näitus „Kuu rootsi kunstnikku", Universa Haus, Nünberg (28.08.-12.10.1958).

(1958), 53-36; [Endel] $K[\tilde{o} k s]$ Kunstikroonika"“, Mana, 4(3) (1958), 64 
Sellega olevat hakatud tegema ruumi, andma pildile mõõdet, vähenenud on kujundite osakaal. Kõksi abstraktsus olevat muutunud dünaamilisemaks. ${ }^{24}$ „Muinasjutu“ puhul on ometi kord näha paljuräägitud Joan Miró mõju, kuid autorit teadmata määraksin ma selle hoopis Karin Lutsu värviliseks graafikaks (vrd „Minu aed“, 1968). Miró mõjutusi on aimata ka paljukiidetud „Carmina buranas" (1959), mida Max Lasberg on iseloomustanud „kõrgetemperatuurilise, kohati lausa hõõguvana“25 ja selle paarikus „Carmina atomicas" (1963). ${ }^{26}$ "Teravselgete värvidega kainelt ja optimistlikult mõjuv“27 töö „Eile ja täna“ on rahulikumat laadi ning näitab suunda hilisema suurejoonelise abstraktse laadi poole.

1961. aastal oli Kõksil põhjust Arno Vihalemmale kirjutada: „Nagu Sa ise juba oled kuulnud, teen ka mina praegu uut, figuratiivset perioodi läbi ja seda sisemisel - st kõhu - sunnil, sest oma abstraktsest perioodist olen ma saanud aastas keskmiselt 5-6 maali müüa ja sellest ei jätku mul mitte "trahvidegi“ maksmiseks, rääkimata peatoiduse ja ulualuse maksmisest. ${ }^{\prime \prime 28}$ Arvatavasti püüdis Kõks kompromissina ühendada realistlikku tööd abstraktsega peaaegu realistliku portree abil, nagu „Proua G. (Gorpe) portree“ (1959), „Ädu Aunver“ ja „Indrek Aunver" (mõlemad 1963), aga mille taustad on abstraktsed. Samaaegselt algas popkunsti sissetung. Varasematele märkidele ja joontele lisandusid kirjad ja numbrid („Kompositsioon figuuridega“, 1962) ning popkunstile omaselt fotolike ja sensuaalsete portreede paigutamine abstraktsesse maali, nt Sophia Loren („Kiirgusvalem“ / „Formula of Radation“, 1964), Gina Lollobrigida („Karbontsükkel“, 1964), aga ka Silja Rüga jt. Sellises laadis töid on veel kümmekond, olgu siin nimetatud „Külaline ateljees“ (1962) ja „Kiri Ameerikast” (1964). ${ }^{29}$ Väga popilik on ka mõnevõrra erandlik abstraktne natüürmort „Reklaam mõistusele“ (1964). Võimalik, et kujutatud on klassikalist seadeldist, millel erivärvilised kandilised pinnad moodustavad kujundeid (joonlaud jms). Huvitav on see, et kasutatud näib olevat kollaaži, värvilisest paberist ja ajalehtedest rebitud fotosid. Tõepoolest näib, sest pilti lähemalt uurides selgub, et kõik on sinna ainult maalitud. Sama on ülalpool nimetatud "fotodega“ - kõik on pildile maalitud.

24 Reets, „Ajajärk nimega abstraktne“, 80-81; End, „Avangardne Kõks“, 74.

25 Lasberg, ,Ystadi muljed“, 302

26 Kõik kolm mustvalgel fotol.

28 Endel Kôksi kiri Arno Vihalemmale 29. mail 1961. EKL A, reg. 2010/155.

29 Mõlemad mustvalgel fotol.

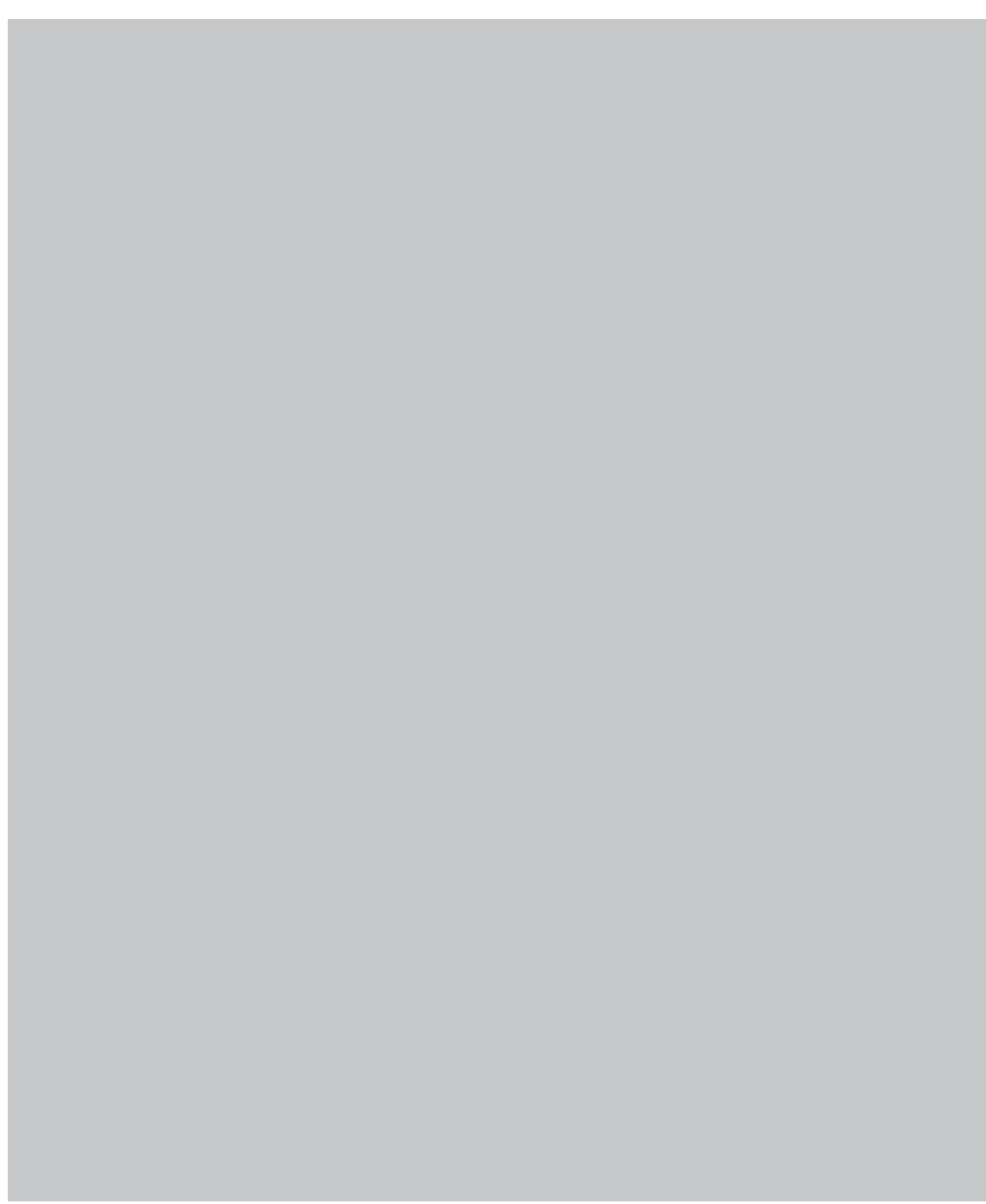

Ill. 3. Endel Kõks, Kiirgusvalem, õli lõuendil, 1964. Erakogu.

Muutus Kõksi puhtasse abstraktsionismi tuli 1963. aastal. Reets on seda iseloomustanud kui „,imelisemat aastat, mida ühe kunstniku elus ootuste päraselt näha saab. Mitte vastu ootust, vaid üle ootuste rikas ja tööde poolest ülirohke. ${ }^{430}$ Kunstnik on hakanud töötama sarjade

30 Reets, „Ajajärk nimega abstraktne“, 84 


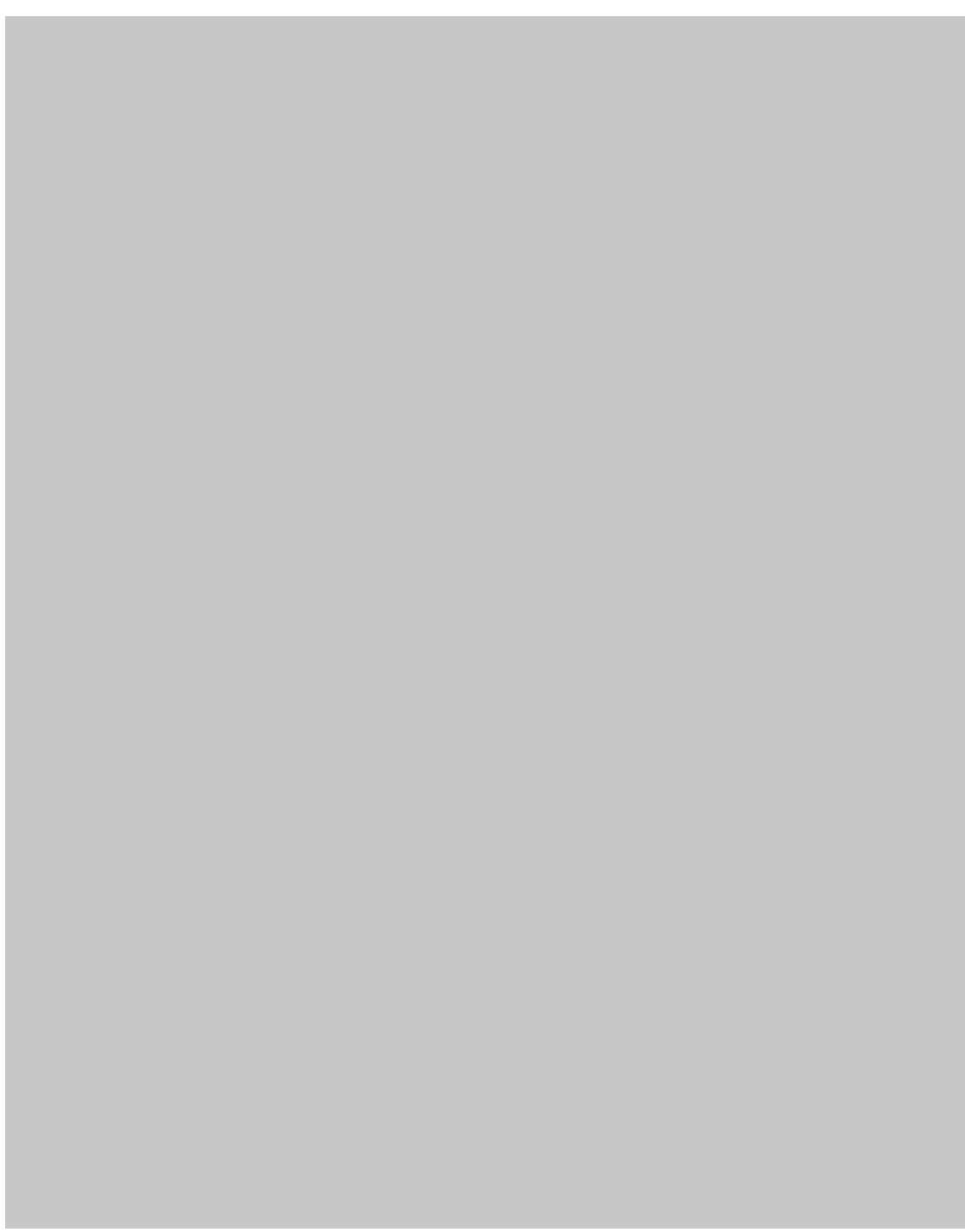

Ill. 4. Endel Kõks, Elektroonika XXIX, akrüül paberil, 1963. Underi ja Tuglase Kirjanduskeskus.

kaupa, millest tuntuim on kahtlemata 36 lehest koosnev „Elektroonika“ (Electronics). ${ }^{31}$ Kõksi enda sõnade järgi tekkis tal vajadus ja mõte luua sari eksperimentaalmuusikat kuulates, eksperimentaalfilmi vaadates ning

31 Reets nimetab veel seeriaid „Oja“, „Exegesis“, „Tants“ jt. Reets, „Ajajark nimega abstraktne“, 84 tuumafüüsikale mõeldes. Loodud küll klaasitrükitehnikas ehk vitrograafias, on iga töö unikaalne äratõmbejärgsete töötluste, värvitilgutamiste, pritsimiste, lisatud pintslitõmmete ja kujundite tõttu. Loomulikult viitab siin kõik Pollockile. Kui aga kandinskilikud spontaansed kompositsioonid mõjusid veenvalt ning tööle hakkas suurepärane värv, siis nende variatsioonide puhul tundub puudu jäävat vajalikust kontrollimatusest, vähemalt näivastki kontrollimatusest. Lehed on küll suurepärases tasakaalus, tilgad, triibud ja kujundid on oskuslikult paika pandud, kuid puudub sellele abstraktsioonile vajalik „,metsik võlu“. Ka koloriit, kuigi osades lehtedes vägagi intensiivne, mõjub hillitsetult ning liialt läbimõelduna. Kirjas Silvia Hinnomile on Kõks arutlenud: „Maalitehnilise probleemi lahendus on tihtipeale või peaaegu alati ühenduses kas ekspressiivse või intellektuaalse probleemiga. Jackson Pollock on seks suurepärane näide. Tema ekspressiivsus, mis on tuntud ka spontanismi või action painting'u nime all, oli ainult maalitehnika, kuid kuna seda tehes kunstnik ise muutus nagu ise maali osaks, muutus tema tehnika otseseks väljenduseks. Siin aitab jälle vaatlemine, et aru saada, kas tegija ise on olnud küllalt angasheeritud sellest, mis ta just on teinud. ${ }^{432}$ Just selle laadi juures näib Kõksil piisav angažeeritus puuduvat.

1962. aastal maalis Kõks abstraktse kompositsiooni „Astraalne“, mis kujutab põneval krobelisuse efekti looval kollakaspruunil pinnal punast ringi ja selle kõrval painutatud violetset ristkülikut. Vaid kahe sümboliga on tekitatud kosmilises ruumis hõljumise tunne. Alates aastatest 19641965 sai selline laad järkjärgult valdavaks ning selles lôi Kõks teosed, milles väljendub kõige ehedamalt tema ande suurus ning „,loodusvormide kujundaja“ võlu. Need tööd on ülesehituselt geniaalselt lihtsad, koosnedes suhteliselt ühtlasele tasapinnale paigutatud sümbolitest ja kujunditest. Maalidest on kadunud närviline rabedus ja kiire liikumine, meeleolu on rahulik ja naudisklev, mulje paljudel piltidel monumentaalne, võidutsema pääsevad meisterlikud, hõrgud värvikooslused ja mida aeg edasi, seda rohkemaks ja põnevamaks muutub ka faktuur. Eevi End on väitnud, et see meele- ja laadimuutus tuli Kõksi töödesse pärast esimest Ameerika (Kanada) reisi 1967. aastal. Kõksi muutumist võib aga näha juba 1965, muutuste aimdusi isegi 1962-1964 monotüüpiates, lisaks „Põlenud kirjas“ ja „Abstraktses motiivis“ (mõlemad 1966). Selline peaks olema ka

32 Endel Kõks kirjas Silvia Hinnomile 1970. aastatel. Koopia autori valduses. 


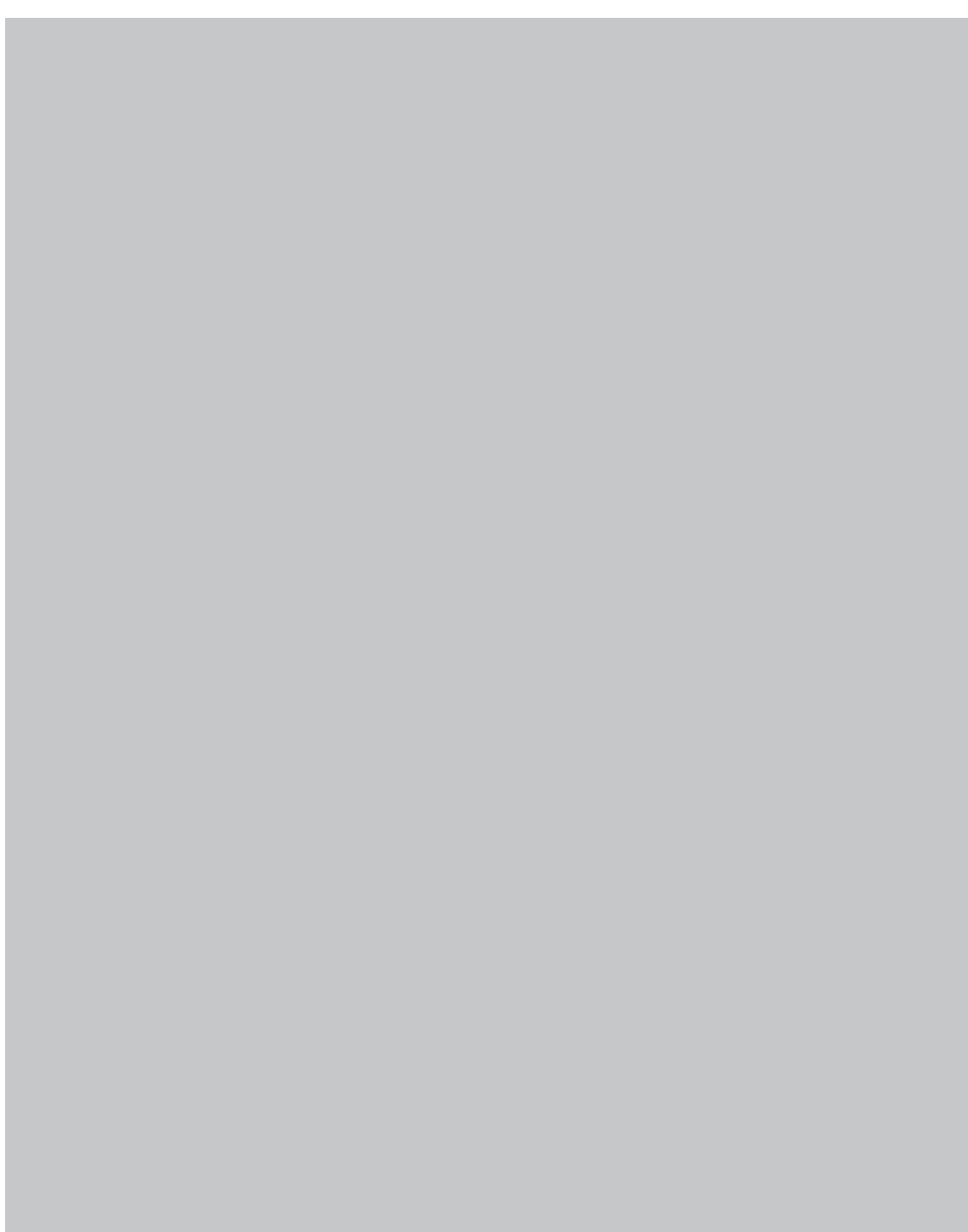

Ill. 5. Endel Kõks, Rõõmukirjad II, õli lõuendil, 1966. Erakogu.

7-9 pildist koosnev sari „,Rõõmukirjad“ („Rõõmukirjad II“, 1966). ${ }^{33}$ Kõks esines „Rõõmukirjadega“ 1966. aasta novembris Torontos Bergtoni galeriis. Sel puhul märkis nende erandlikkuse ära Abel Lee. ${ }^{34}$

33 Artikli autor on näinud ainult kaht selle sarja tööd.

34 Abel Lee, Värv ja Vorm. Sügis saabub kunstiga“" Vaba Eestlane, 05.11.1966, 7.
1965. aastal tunnustas Rootsi Eestlaste Esindus (REE) Endel Kõksi otsinguid kultuuriauhinnaga. Žürii otsus oli harvaesinevalt üksmeelne ning motivatsioonikirjas märgiti, et kunstnik on oma loomingu lähtekohaks seadnud vaimse vabaduse, ta oli üks esimestest, kes hakkas rakendama abstraktse kunsti ideid ja põhjustas eesti kujutavas kunstis uue läbimurde, on palju ja edukalt esinenud näitustel ning tema looming on suunatud tulevikku. ${ }^{35}$

Eevi Endi arvates on Kõksi mõjutanud Ameerikas abstraktsionismi teise maksva suunana tegutsenud 20. sajandi nn kalkservne (hard-edge) koolkond, esindajateks Ellsworth Kelly, Kenneth Noland jt. Nende oluliseks jooneks oli vormide kindel ning selge piiramine ja värvide indiferentsus, kuigi pigem oli tegemist värvipindade kui vormidega. Koolkonna noorema generatsiooni tööd olid maalilisejärgse abstraktsionismi (postpainterly abstraction'i) stiilis ning selle pehmemasse külge on ta asetanud ka Endel Kõksi. ${ }^{36}$ Kõks ise on oma abstraktsed pildid paigutanud biomorfilisse abstraktsionismi, mille tunnuseks on vaba formalism, ruumilikkus ja atmosfäärilikkus (Arshile Gorky, William de Kooning, Mark Tobey, Mark Rothko, Jackson Pollock.) ${ }^{37}$ Siia kuulub muidugi ka Vassili Kandinsky, keda Kõks ise maininud ei ole. Need mehed olid kõik varasemad ning ei loobunud oma piltides maalilisusest nagu Kõks isegi. See sobis hästi Kõksi looduse kujundamise ideega, et kunstnik võtab loodusest kujundi ning loob sellest uue abstraktse kujundi, säilitades objekti vaimsuse. ${ }^{38}$

Kõks tundis huvi erinevate rahvaste mütoloogiate vastu. Pärast Ameerikasse jõudmist ilmusid tema maalidesse indiaanlaste sümbolid. Mehhiklased mõjutasid teda kindlasti oma looduse ja elukeskkonna soojade eredavärviliste toonide ja puhaste värvipindadega. Ilmselt PõhjaAmeerikast on pärit lood ning suured selged kujundid ja sümbolid, mida ta siis enda äranägemist mööda töötles. Kõks poleks aga loomulikult Kõks, kui ta ka selles laadis ei liiguks mitmesse erinevasse suunda. Võimalik on eristada vähemalt kolme-nelja erinevat lähenemisviisi.

Esimese puhul on tähtsaim osa taustal, millel erineva faktuuri, värvi ning võimalik, et aeg-ajalt kollaažiga ${ }^{39}$ on loodud enamasti ruumiline

35 Madis Üürike, „Kultuuriauhind Endel Kõksile“, Mana, 1-2 (1965), 72.

36 End, „Avangardne Kõks“', 75 .

37 Endel Kõk kirjas Silvia Hinnomile 1970, aastatel. Koopia autori valuses.

38 Vt Madis Üürike, „Intellektuaalne Kõks", Mana, 2 (1962), 122.

39 Kollaaže on nimetatud juba 1954. aasta näituse kataloogis, kuid sinkirjutajal pole olnud võimalust neid näha. 


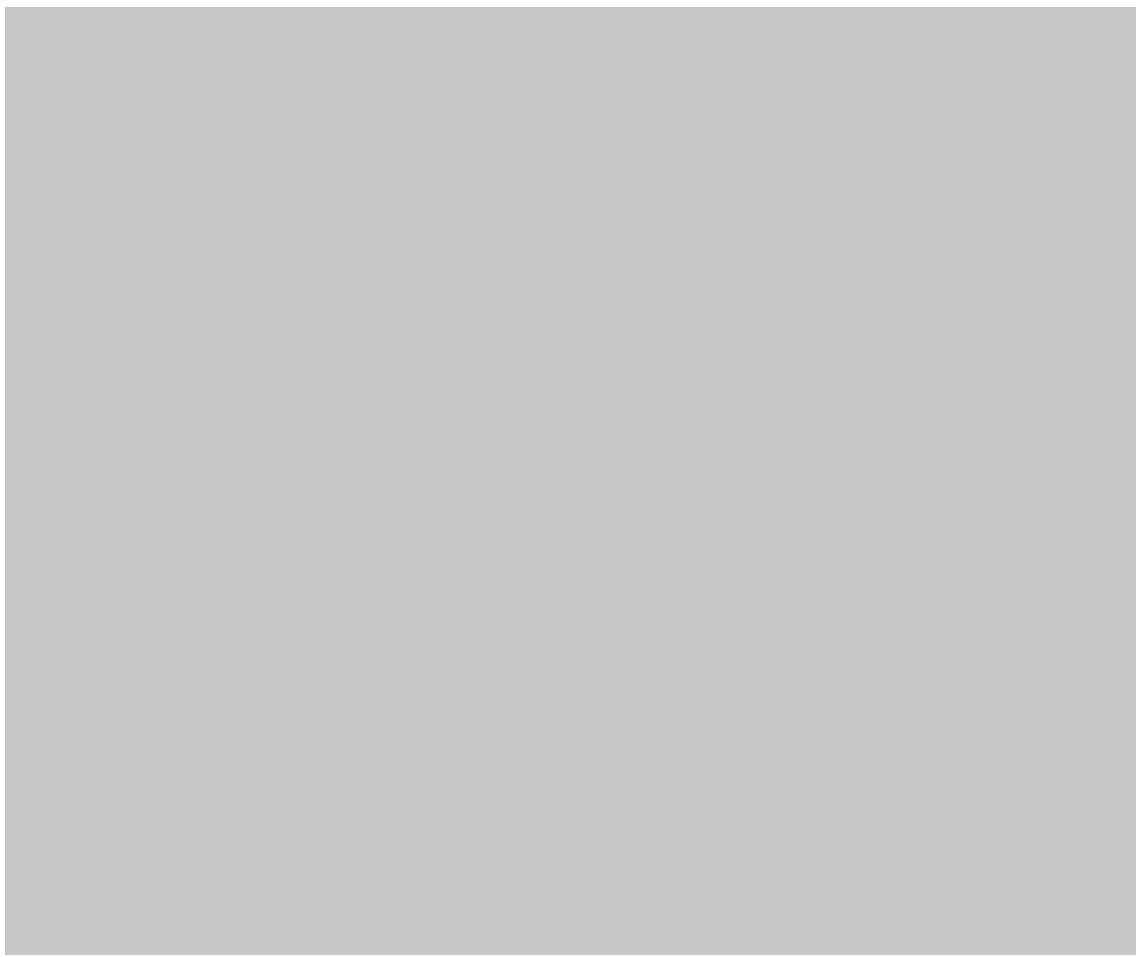

Ill. 6. Endel Kõks, Astraalne, õli, monotüüpia, 1964. Erakogu.

efekt. Tausta peal asetsevad aktsendina üksikud kujundid, nagu töödes „Valge mälestus" (1967), „Õhustik“ (1969) ja juba nimetatud „Astraalne“ (1962).

Teises, kõige mõjuvamas ning nauditavamas laadis, eralduvad erakordselt hästi läbitöötatud, kuid vaoshoitud taustal võimsad äratundmatud sümbolid, näiteks töödes „Calceolaria“ (1967), ,"Kompositsioon sinisega“ (1967), „Espaceonada“, „Kaljud“ ja „Savi“ (kõik 1969). Siia kuulub ka sari „Rõõmukirjad“.

Kolmandaks on tööd, millel tausta ja sümboleid eraldada ei saa. Nende puhul võib aimata, et jutustatakse mingit lugu või kujutatakse kindlat vaadet, nagu töödes „Abstraktsioon punase joonega“ (1967), „Kompositsioon kollase Päikesega“ (1967), „Kolmas seitsmest Päikesest” (1970), „Keskööpäike“ (1975) (ilmselt kogu seitsmest maalist koosnev „Päikese ${ }^{\text {"40 }}$ sari) ja kümnest maalist koosnev sari „Kümme käsku“ (1969).

40 Põhja-Ameerika indiaani legend räägib viiest erivärviliste päikeste ajastust (punane, sinine, kollane, valge/must ja hall). Hetkel elame halli päikesega maailmas. Vt Endel Kõks, „Siksika ja Pocahonta ehk lugu viiest päikesest", Eesti Päevaleht, 10.07.1974, 2

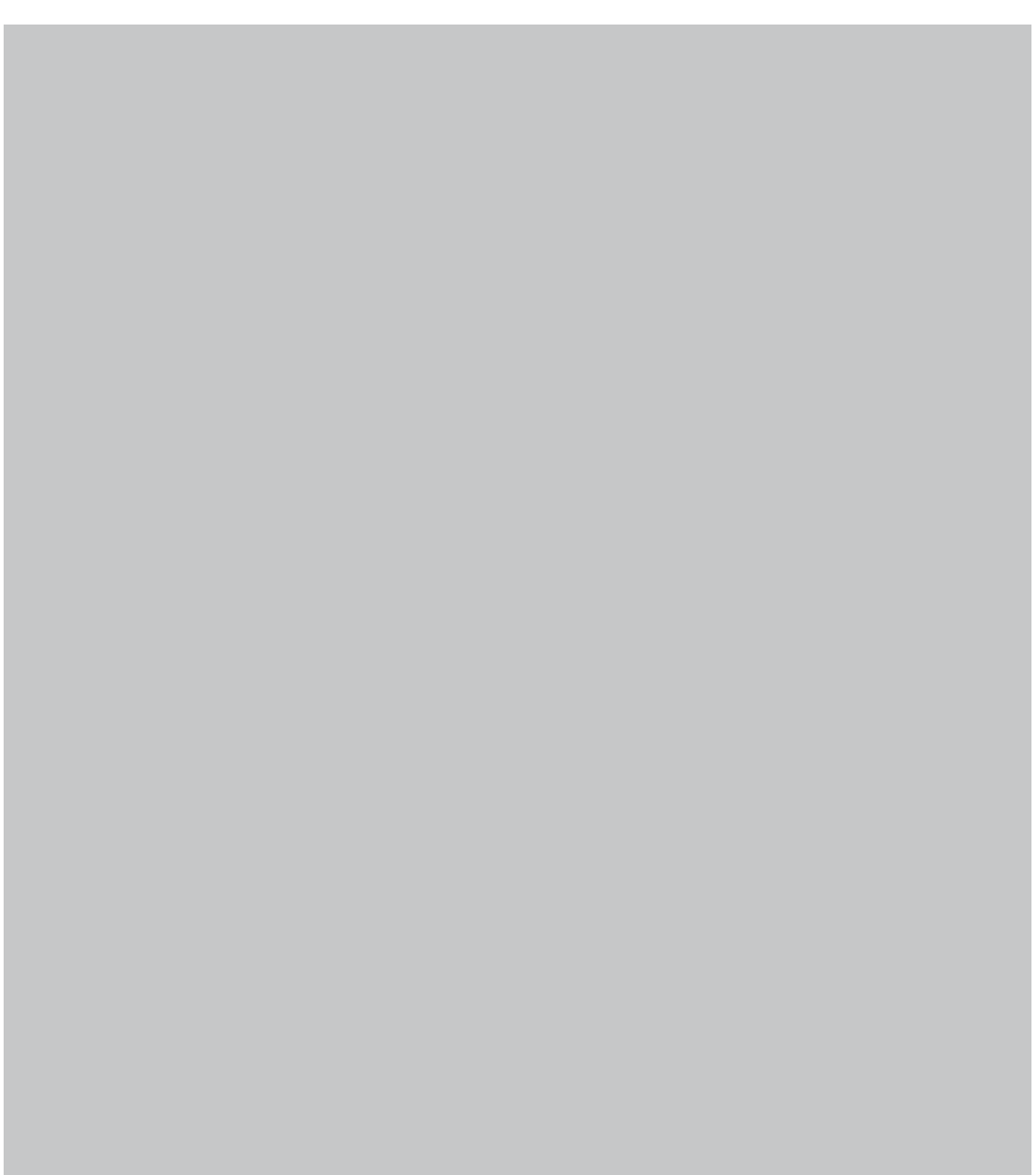

Ill. 7. Endel Kõks, Espaceonada, õli lõuendil, 1968. Erakogu.

Neljas lähenemisviis koondab kõigi eelnevalt nimetatute jooni: taust ja sümbol on võrdselt tähtsad, sümbol on kujutatud suurelt ning võimalik on aimata lugu või kujundit. Kuna sellised pildid tunduvad olevat valminud kõige hiljem, on selline sümbioos päris loogiline. Siia võiksid kuuluda tööd "Neli mõõdet“ ja "Kohatunne“ (mõlemad 1970), „Kevade märgid“ ja „Talve märgid“ (mõlemad 1979), samuti vähemalt kolmest maalist koosnev sari „Sigma X“ (kuldooker, roosa ja roheline, 1970-1977). Aeg-ajalt on nende laadide vahele sattunud veel iselaadsemaidki töid. Aja jooksul on üha suurema tähtsuse omandanud faktuur. Värvipindu on kraabitud, kasutatud on erinevat 


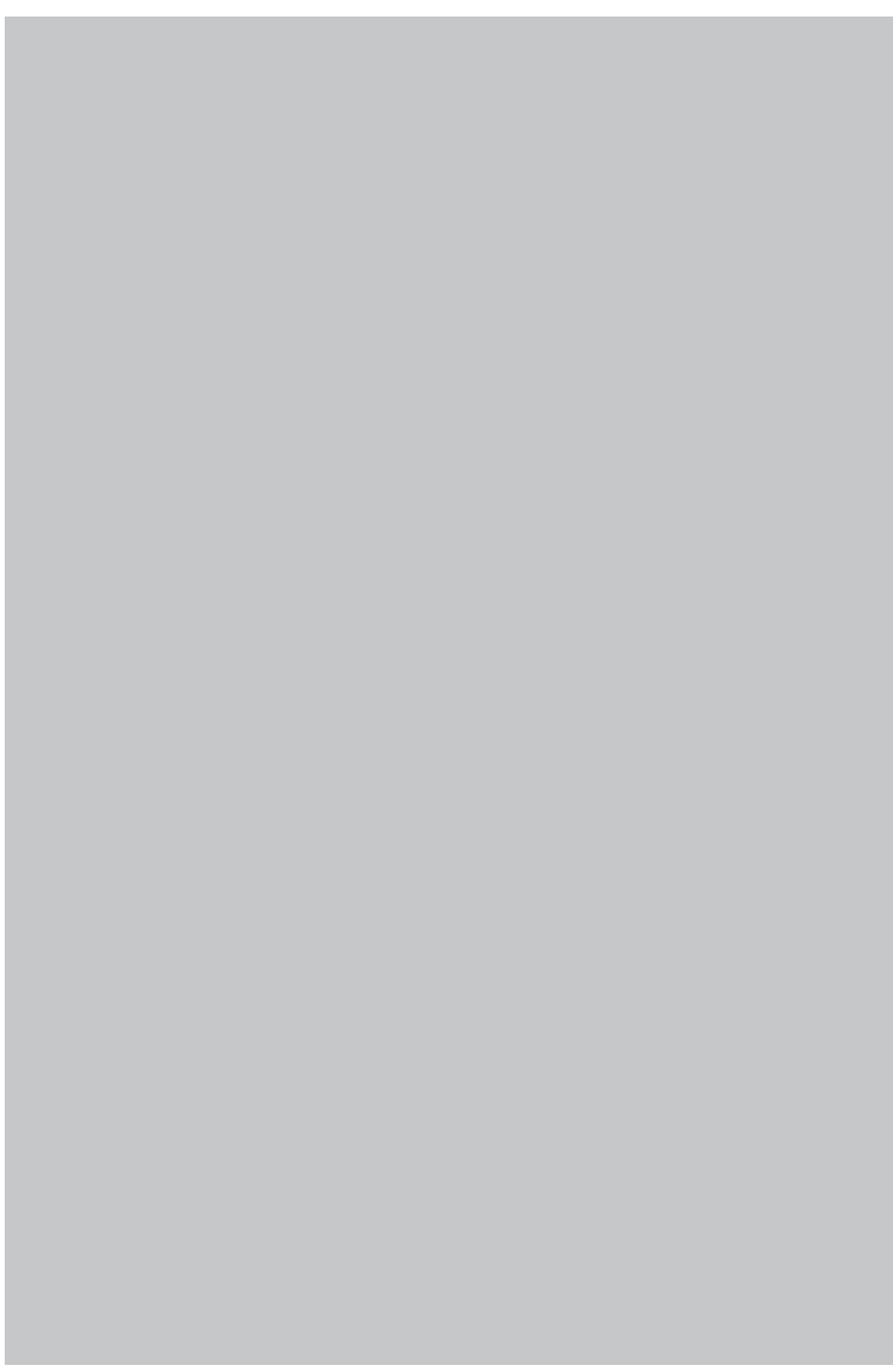

Ill. 8. Endel Kõks, Keskööpaike, akrüül lõuendil, 1975. Eesti Kunstimuuseum SA.

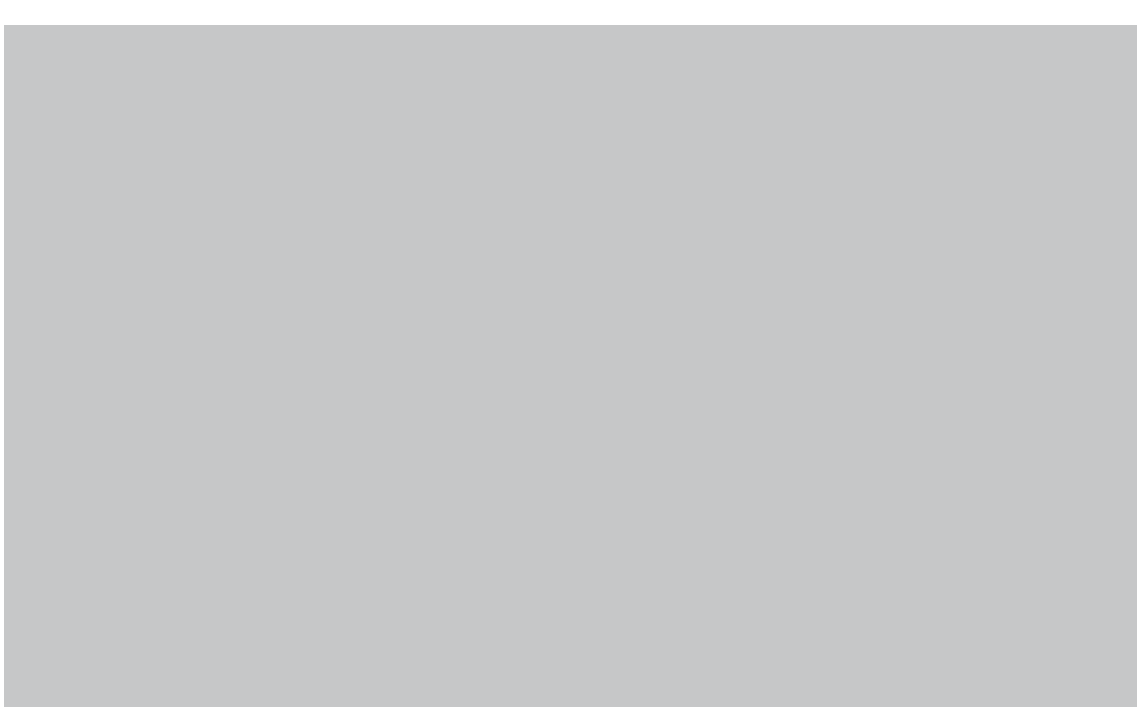

Ill. 9. Vaade Endel Kõksi loodud sarjale „Kümme käsku“. Foto: Reet Mark.

pintslikirja, vormitud kujundeid. Värvid on väga eredad ja on saavutanud erilise läbipaistvuse ning hõõguva efekti. Mitte mingil juhul ei saa enam väita, nagu poleks koloriit Kõksile olnud esmatähtis. Nendes abstraktsioonides allub kõik kummalistele värvikooslustele, lõõskavale, julgele ja näiliselt kontrollist vabale, pakkudes rabavaid iluelamusi. Ja loomulikult ei saa siin rääkida pallaslikust (mahedast toon toonis) maalilaadist.

Olime USA-s Lakewoodis, just käinud eesti kirikus Kõksi maalitud altarimaali vaatamas. Tegemist oli figuraalse jutustava tööga. Ma ei olnud veel näinud Kõksi parimaid abstraktseid töid Kanada erakogudest. Altar oli jätnud tavalise, natuke õlgu kehitama paneva mulje, mis tekib tihti ka tema reisipiltide ja indiaaniainelise graafika puhul. Sõitsime Harry Musta vanema poja poole, kelle majas pidi asuma suurem osa kogusse kuuluvaid Kõksi pilte. Maja oli suur ja ebakorrapärane. Äkitselt seisime hallis, mis ulatus läbi kahe ja poole korruse ning vaatasime otsa kümnele, viie kaupa kahes reas seisvale suurele pildile ning nende kõrval veel hõõguvpunasele ja mustale, ilmselt „Päikese“ sarja tööle. Need kümme maali moodustasid sarja „Kümme käsku“ (1969) ${ }^{41}$

41 Silvia Hinnom on kirjutanud: „Tean Harry Musta käest, et Köks oli seletanud ainult ühe sarja "Kümme käsku - kohta, et vasakul asuvate kitsaste joonte arv nätas kaskude numbreid ja maaling autorile 21. novembril 2011. anstal. Kiri autori valduses. 
- abstraktsed, vapustavalt kumavate värvidega, maalitud majesteetliku rahu ja eneseleidmise kindlusega. Tekkis sama tunne, kui satud kiljuvast baroksest katedraalist romaani kiriku enesekindlasse vaikusse. Otsekohe tuli kindel äratundmine, et Kõks on suur meister, kelle abstraktsete tööde kõrval jääb varju kõik ta saatusekaaslastest kunstnike samas laadis tehtu. Selgitamisel ja põhjendamisel, ni nagu ka püüetel abstraktset maali kirjeldada, ei näi siin olevat suuremat mõtet.

Juba oma varajases loomingus oli Endel Kõks suur katsetaja ning erinevate laadidega töötaja. Järk-järgult liikus ta abstraktse suuna poole ning oleks selleni jõudnud ilmselt veel varem, kui vahele poleks tulnud sõda. Picassolik, abstraktsuseni viiv figuurideformatsioon ning kandinskilik abstrakstioon muutusid talle oluliseks juba 1950. aastate alguses. Läbinisti abstraktsete töödeni jõudis Kõks aastaks 1956 (?). 1960. aastate esimesest poolest lisandusid ta töödesse popkunsti elemendid. Katsetades pollockliku action painting'uga, mis minu meelest ei andnud eriti veenvaid tulemusi, jõudis ta 1960 aastate teisel poolel dekoratiivse, suurepäraselt sobivate ergaste, eriliselt hõõguvate värvide ning suurte sümbolitega loodud rahutu faktuuriga kompositsioonideni. Selles laadis lõi ta oma olulisemad tööd. Kõksi intellektuaalne, läbimõeldud kujunditega abstraktsioon on täiesti vastandlik Elmar Kitse suurepärasele spontaansele värvikülluslikule abstraktsioonile. Kits jääb pallasliku värvitraditsiooni juurde, Kõks murrab sellest välja. Kõks tunneb end abstraktseid pilte maalides kindlalt ja naudib mängu, mida ei saa sugugi väita Lepo Mikko või Alfred Kongo läbinisti abstraktsete tööde puhul Selles väites kõhklejatele tuleb meenutada, et Kõksi abstraktsetele piltidele hinnangu andmiseks peab olema neid näinud Euroopas, USA-s ja Kanadas. Ainult Eestis asuvate tööde põhjal ei saa järeldusi teha. Abstraktsionistina pole ta mingil juhul nõrgem oma põlvkonnakaaslastest, lihtsalt väga erinev ja paremuse määramine on siinkohal maitseküsimus.

Kõksi maalilooming ei ole ühtne, teadlikult ei kujundanud ta välja kindlat käekirja ja selle puudumist pidas ta oma tugevuseks. Töötamine nii mitmes erinevas suunas ei näita mitte veendumuste puudumist, vaid enda vabana tundmist. Ühena vähestest pagulaskunstnikest mõistis ta rahvusvahelisse kunstiellu suundumise tähtsust ning suutis sinna ka tagasihoidlikul määral läbi murda.
Endel Kõksi suurus seisneb selles, et ta suutis haakuda maailma kunstis toimuvaga, proovis uued suunad enda jaoks läbi ning pani nendest lõpuks kokku midagi uut iseenesele, arendades seeläbi eesti kunsti tervikuna.

Reet Mark: Endel Kõks's Abstract Paintings

Keywords: Estonian Art in Exile; Abstractionists' Painting; abstractionism; Pallas; Endel KõKs

SUMMARY:

The artist Endel Kõks (1912-1983) is a member of the same generation of Estonian art classics as Elmar Kits and Lepo Mikko. After Kits's and Kõks's debut at the exhibition of the Administration of the Cultural Endowment's Fine Art Foundation (KKSKV) in Tallinn in 1939, the three of them started to be spoken about as the promising Tartu trio. In 1944, Endel Kõks ended up in Germany as a wounded soldier, while Kits and Mikko remained in Estonia. The Kõks's works that have surreptitiously arrived in his homeland are incidental and small in number Thus, without any proof, an image developed or was developed of him in Soviet-era art history as a mediocre painter and especially as a weak abstractionist, which is somewhat prevalent even today. I would dispute this based on the conclusions that I reached when helping to organise the exhibition of exile Estonian art between 2008 and 2011 $1^{42}$ and Endel Kõks's solo exhibition between 2011 and 2013³; conclusions that I have supplemented with the opinions expressed by exile Estonian art historians and artists.

In 1951 Kõks moved to Sweden. Paul Reets has highlighted the years between 1952 and 1956, and assumed that these were difficult years due to the contradictions he faced. According to Reets, one obstacle was

42 Exhibition Eesti kunst paguluses at Kumu (03.09.2010-02.01.2011) and Tartu Art Museum (23.02.2011-30.04.2011). Curators: Kersti Koll, Reet Mark ja Tiiu Talvistu.

(14.11.2012 24.03.2013). Curators: Reet Mark, Reet Pulk-Piatkowska ja Tiiu Talvistu. 
influence of the Pallas on Kõks's painting style, which was conservative and adhered to the trends of Late Cubism. ${ }^{44}$ According to both Eevi End and Paul Reets, Kõks painted his first abstract painting in 1956 (Rahutus (Restlessness) according to the former and Konflikt (Conflict) according to the latter). A black-and-white photo exists of Restlessness, which is slightly reminiscent of Pollock, and this is not the same work that P. Reets refers to. They both note that this was a convincing and mature abstraction not a searching for form, and as Reets states, Kõks had severed himself from the Pallas. ${ }^{45}$

The abstract paintings created between 1956 and 1960 - Kompositsioon (Composition) (1958), Rõõmus silmapilk (Joyful Moment) (1959) and others are constructed on the impact of a joyfully colourful palette and lines, and demonstrate a kinship with the abstract works of Vassili Kandinsky. There is also a similarity to Arshile Gorky, whose works he may have seen at the exhibition of modern American art in Stockholm in 1953.

Kõks's transition into a pure form of abstraction occurred in 1963. Reets has characterised this as a "the most wondrous year that one can expect to see in an artist's life. Not an unexpected year, but one that was unexpectedly and extremely rich when it came to his works." ${ }^{\prime \prime 6}$ The artist started to create series of works, of which the best known is undoubtedly Elektroonika (Electronics), which was comprised of 36 sheets. ${ }^{47}$ According to Kõks, he developed the need and idea to create the series while listening to experimental music, watching experimental films and thinking about nuclear physics. Created with a glass printing technique, or vitreography, each work is unique due to the post-printing processing, paint dripping, spraying and additional brushstrokes and images. Of course, all this alludes to Jackson Pollock.

In 1962, Kõks painted the abstract composition Astraalne (Astral), which depicts a red circle and bent violet rectangle next to it on an interesting yellowish-brown surface that creates a rough effect. Using only these two symbols, the artist creates a sense of floating in cosmic space. Starting in 1964-1965 this style gradually came to dominate his work, and in was in this style that Kõks created the works that express the greatness of his talent and the charm of the "shaper of nature forms" in the purest sense.

44 Paul Reets, Ajajärk nimega abstraktne, 80-81.

45 End, „Avangardne Kõks"', 73; Reets, „Ajajärk nimega abstraktne“, 81

Ajä̈rk nimega abstraktne“, 84

47 Reets also mentions the series called Oja (Stream), Exegesis, Tants (Dance) etc. Ibidem.
The construction of these works is brilliantly simple, and comprised of symbols and images placed on a relatively uniform surface. The nervous brittleness and rapid movement have disappeared from the paintings. The mood is calm and reveling. There is a monumental feel to many of the pictures. Masterful, delicate colour combinations triumph. And as time goes on, the more abundant and interesting the texture becomes. Eevi End believes that Kõks was influenced by Ellsworth Kelly, Kenneth Noland and other representatives of the school of Hard-edge painting that other influential direction operating in American abstractionism during the $20^{\text {th }}$ century. Kõks himself has defined his abstract paintings as biomorphic abstraction, characterized by a free formalism, spatiality and atmospherics (Arshile Gorky, William de Kooning, Mark Tobey, Mark Rothko, and Jackson Pollock. $)^{48}$

Kõks's abstraction that features intellectual and cognizant images is totally the opposite of Elmar Kits's excellent and spontaneous colourfu abstraction. Kits remains true to the Pallas colour tradition; Kõks breaks out of it. Kõks feels secure painting abstract pictures and enjoys the game, which cannot be said of the thoroughly abstract works of Lepo Mikko or Alfred Kongo. Those who doubt this statement should remember that, in order to provide an assessment of Kõks's abstract pictures, one must have seen them in Europe, the U.S. and Canada. Conclusions cannot be drawn based exclusively on the works in Estonia. As an abstractionist he is in no way weaker than his contemporaries, just very different and the determination of superiority is a matter of taste. Endel Kõks's greatness lies in the fact that he was able to fit with what was happening in world art (which many exile artists could not); he experimented with new directions and finally put together something new for himself, and thereby developed Estonian art as a whole. 
CV:

Reet Mark (b. 1965) is an Estonian art historian interested mainly in $20^{\text {th }}$ century Estonian art. She worked for many years at the Tartu Art Museum, now at the Estonian National Museum. A member of the Estonians Artists' Association, the Estonian Society of Art Historians and Curators and ICOM. She has published more than 100 exhibition reviews, articles on Estonian art history and four monographic publications on Estonian artists. She has also curated more than 50 exhibitions at the Tartu Art Museum, Art Museum of Estonia and the Estonian National Museum. 